\title{
Analysis of Cellular and Protein Content of Broncho-Alveolar Lavage Fluid from Patients with Idiopathic Pulmonary
}

\section{Fibrosis and Chronic Hypersensitivity Pneumonitis}

\author{
Herbert Y. Reynolds, Jack D. Fulmer, John A. Kazmierowski, William C. Roberts, \\ Michael M. Frank, and Ronald G. Crystal \\ From the Laboratory of Clinical Investigation, National Institute of Allergy and Infectious Disease; the \\ Pulmonary Branch, National Heart and Lung Institute; and the Section of Pathology, National \\ Heart and Lung Institute, National Institutes of Health, Bethesda, Maryland 20014
}

\begin{abstract}
A B S T R A C T To evaluate cellular and protein components in the lower respiratory tract of patients with idiopathic pulmonary fibrosis (IPF) and chronic hypersensitivity pneumonitis (CHP), limited bronchoalveolar lavage was done in 58 patients ( $19 \mathrm{IPF}, 7 \mathrm{CHP}$, and 32 controls). Analysis of the cells and protein in the lavage fluids from patients with IPF revealed an inflammatory and eosinophilic response and a significant elevation of IgG in the lungs. With corticosteroid therapy, inflammation diminished but eosinophils remained. Lavage fluid from patients with CHP also had eosinophils and elevated levels of IgG. However, in contrast to IPF, lavage fluid from CHP patients contained IgM, fewer inflammatory cells, and a strikingly increased number $(38-74 \%)$ of lymphocytes. Identification of lavage lymphocytes in CHP showed that $\mathrm{T}$ lymphocytes were significantly elevated and B lymphocytes were decreased compared to peripheral blood. These studies stiggest that the lung in IPF and CHP may function as a relatively independent immune organ, and that analysis of cells and proteins in broncho-alveolar lavage fluid may be of diagnostic, therapeutic, and investigative value in evaluating patients with fibrotic lung disease.
\end{abstract}

This paper was presented in part at the American Federation for Clinical Research, Atlantic City, N. J., 2 May 1976. An abstract appeared in 1976 Clin. Res. 24: 388.

Requests for reprints may be addressed to: Ronald G. Crystal, Room 6D06, Building 10, National Institutes of Health, Bethesda, Md. 20014.

Received for publication 14 June 1976 and in revised form 29 September 1976.

\section{INTRODUCTION}

The fibrotic lung diseases are a heterogeneous group of chronic, usually fatal disorders, characterized radiographically by a pattern of interstitial infiltration and physiologically by the loss of lung volume and a decrease in diffusing capacity. Histologically there is cellular infiltration of alveolar septa and an apparent increase in parenchymal collagen $(1,2)$.

Although some patients with pulmonary fibrosis can be grouped according to etiology (e.g., occupational, environmental, infectious, tumor, or drug) or by characteristic lung histology (e.g. eosinophilic granuloma), many can be classified only as having "idiopathic pulmonary fibrosis" (IPF). ${ }^{1}$ Although the term 'IPF' implies that the etiology and pathogenesis of the disorder is unknown, there are clues which suggest that inflammatory and/or immune-mediated mechanisms are related to the continued activity of the disease (3).

In contrast to IPF, chronic hypersensitivity pneumonitis (CHP) is a group of fibrotic lung diseases in which the etiology is often known. With chronic inhalation of certain organic antigens, susceptible individuals develop a granulomatous interstitial disease which often leads to significant parenchymal fibrosis (4). Animal studies have suggested that in hypersensitivity

\footnotetext{
${ }^{1}$ Abbreviations used in this paper: $\mathrm{CHP}$, chronic hypersensitivity pneumonitis; C4, C6, hemolytic complements; $\mathrm{E}$, erythrocyte; $\mathrm{FEV}_{1} / \mathrm{FVC}$, forced expiratory volume (1 s)/ forced vital capacity; IPF, idiopathic pulmonary fibrosis; $\mathrm{PaO}_{2}$, mean resting arterial blood oxygen tension; PMN, polymorphonuclear leukocytes; SRBC, sheep red blood cells.
} 
pneumonitis, local immune reactions in the lungs, involving both humoral and cellular mechanisms, are intimately related to the pathogenesis and activity of the disease process $(5,6)$.

Our understanding of these diseases, however, is restricted by limitations in the technologies available for their study. Lung tissue is not accessible for repeated studies and radiographical, physiological, and peripheral blood studies do not give a true assessment of the dynamic inflammatory and immune mechanisms operating in the local environment of the lung. The present study attempts to evaluate these mechanisms through an analysis of cellular and protein components in broncho-alveolar lavage fluid from a representative portion of the epithelial surface of the lower respiratory tract in patients with IPF and CHP.

\section{METHODS}

Study patients. A total of 26 patients, 19 with IPF and 7 with CHP, were included in this study. All underwent extensive clinical evaluation including bronchoscopy and 20 had open biopsies of the lung.

The mean age of the 19 patients with IPF was $50.0 \pm 3.5 \mathrm{yr}^{2}$ 12 were men and 7 were women. All patients with IPF met the following criteria: an interstitial pattern on chest film, reduced total lung capacity, reduced lung compliance, reduced single breath diffusing capacity, resting hypoxemia which worsened with exercise, and a normal forced expiratory volume $(1 \mathrm{~s}) /$ forced vital capacity $\left(\mathrm{FEV}_{1} / \mathrm{FVC}\right)$. None had a significant environmental exposure, symptoms suggestive of hypersensitivity lung disease, left ventricular cardiac failure, or history of chronic pulmonary infections. 17 of the 19 patients with IPF had lung biopsies done within 2-11 mo before the broncho-alveolar lavage study. All biopsies showed septal fibrosis, septal cellular infiltration, and intra-alveolar cellularity. None had granuloma and none had refractile particles under polarized light microscopy. Seven patients currently smoked cigarettes. One patient had joint symptoms compatible with a collagen-vascular disease but had no supporting serologic evidence; one patient had a positive rheumatoid factor (titer $1: 64$ ) but no stigmata of joint disease; and one had positive antinuclear antibodies and was believed to have a mixed collagen-vascular disease.

Seven patients were untreated at the time of bronchoalveolar lavage; the other twelve were receiving prednisone (mean dose 24.4 $\pm 4.0 \mathrm{mg}$ daily). Peripheral blood values, including hemoglobin $(14.0 \pm 0.5 \mathrm{~g} / 100 \mathrm{ml})$, total leukocytes $\left(8,300 \pm 747 \mathrm{cells} / \mathrm{mm}^{3}\right)$, and percentage of lymphocytes on peripheral smear $(27.0 \pm 3.3 \%)$ were within normal limits for all 19 patients.

For untreated patients with IPF, the mean vital capacity was $64.0 \pm 5.0 \%$ of predicted normal values, functional residual capacity was $68.4 \pm 7.4 \%$ predicted, total lung capacity was $65.7 \pm 5.6 \%$ predicted, but $\mathrm{FEV}_{1} / \mathrm{FVC}$ was normal. Carbon monoxide diffusing capacity was $48.3 \pm 6.9 \%$ predicted. The mean resting arterial blood oxygen tension $\left(\mathrm{PaO}_{2}\right)$ for this group was $71.6 \pm 5.0 \mathrm{~mm} \mathrm{Hg}$ (on room air) and decreased to $49.0 \pm 2.5 \mathrm{~mm} \mathrm{Hg}$ with exercise. The latter was done with a graded steady-state exercise protocol, each work level was for $6 \mathrm{~min}$ with arterial blood gases determined during the last 2 min.

${ }^{2}$ All data are presented as mean \pm SEM.
For treated patients with IPF, these parameters were similar. The mean vital capacity was $66.7 \pm 4.2 \%$ predicted, functional residual capacity was $63.0 \pm 3.6 \%$ predicted, total lung capacity was $63.8 \pm 4.4 \%$ predicted, and the $\mathrm{FEV}_{1} / \mathrm{FVC}$ was normal. The carbon monoxide diffusing capacity was $46.0 \pm 3.7 \%$ predicted, while the resting $\mathrm{PaO}_{2}$ was $73.3 \pm 4.2 \mathrm{~mm}$ $\mathrm{Hg}$ and decreased to $53.7 \pm 2.1 \mathrm{~mm} \mathrm{Hg}$ with exercise.

Seven additional patients were referred to us as having IPF, but the episodic nature of the respiratory symptoms, serological studies, or histopathology of the lung biopsy suggested they had a form of hypersensitivity pneumonitis. All of the patients had a history of chronic intermittent respiratory and systemic symptoms related to their home or work environment. Four of the patients had acute episodes characterized by chills and fever accompanied by cough and dyspnea. The other three had a more insidious onset of cough and progressive dyspnea with no chills or fever. Four patients noted relief of symptoms when removed from their home or work environment and an exacerbation of symptoms with re-exposure to the apparent source of antigens. In four patients, the chest X-ray abnormalities have tended to persist even with removal from the apparent antigenic source. The mean physiologic data for these seven patients were: vital capacity, $82.1 \pm 6.4 \%$ predicted; functional residual capacity, $70.2 \pm 5.6 \%$ predicted; total lung capacity, $80.4 \pm 5.3 \%$ predicted; $F_{E V} / F V C$ normal (in all patients), carbon monoxide diffusing capacity, $66.1 \pm 6.4 \%$ predicted. The mean $\mathrm{PaO}_{2}$ was $76.1 \pm 6.4 \mathrm{~mm} \mathrm{Hg}$ and decreased to $68.2 \pm 4.8 \mathrm{~mm} \mathrm{Hg}$ with exercise. Additional clinical and laboratory information about individual patients with CHP is given in Table I.

Control patients. 32 patients ( 20 men, 12 women) with undiagnosed lesions limited to the right upper lung underwent broncho-alveolar lavage in the lingula or left lower lobe as part of the diagnostic bronchoscopy (7). 21 smoked cigarettes and 11 did not. None had evidence by physical examination or chest $\mathrm{X}$ ray of disease in the left lung and none were receiving drugs. The controls were age-matched for the IPF patients (nonsmokers $52.0 \pm 3.0 \mathrm{yr}$; smokers $48.0 \pm 2.4 \mathrm{yr}$.

Bronchoscopy and broncho-alveolar lavage. Informed consent was obtained from all patients. Patients were premedicated intramuscularly with atropine $(0.6 \mathrm{mg})$ and diazepam $(10 \mathrm{mg})$; topical lidocaine spray $(2 \%)$ was used to obtain local anesthesia in the respiratory tract. Bronchoscopies were performed transnasally with a flexible fiberoptic instrument (model BFT 5B-2, Olympus Corporation of America, New Hyde Park, N. Y.). Bronchoscopy was done in the morning, approximately $3 \mathrm{~h}$ after prednisone was given to patients receiving this medication. The procedure was done with constant cardiac monitoring and with an intravenous infusion in place. If the resting arterial $\mathrm{PO}_{2}$ on room air was below $70 \mathrm{~mm} \mathrm{Hg}$, the bronchoscopy was done with supplemental oxygen given by nasal prongs or face mask (with side port for the instrument).

After routine examination of the major airways, the bronchoscope was positioned in a segment of the lingula (B4 or 5). A total of $100 \mathrm{ml}$ of sterile $0.9 \%$ saline (Abbott Laboratories, North Chicago, Ill.) was infused $(30 \mathrm{ml}$ twice and then $40 \mathrm{ml}$ ) and aspirated by suction after each infusion. The lavage fluid was immediately strained through a single layer of gauze to remove gross mucus and then centrifuged $(500 \mathrm{~g}$, $5 \mathrm{~min}$ ) to separate cellular and protein components. The supernate was carefully decanted from the cell pellet for subsequent protein analysis.

Cellular analysis. The cell pellet was resuspended in modified Hank's balanced salt solution (without calcium and magnesium ions) and pelleted again with low-speed centrifugation. The cells were assayed for total number (model 


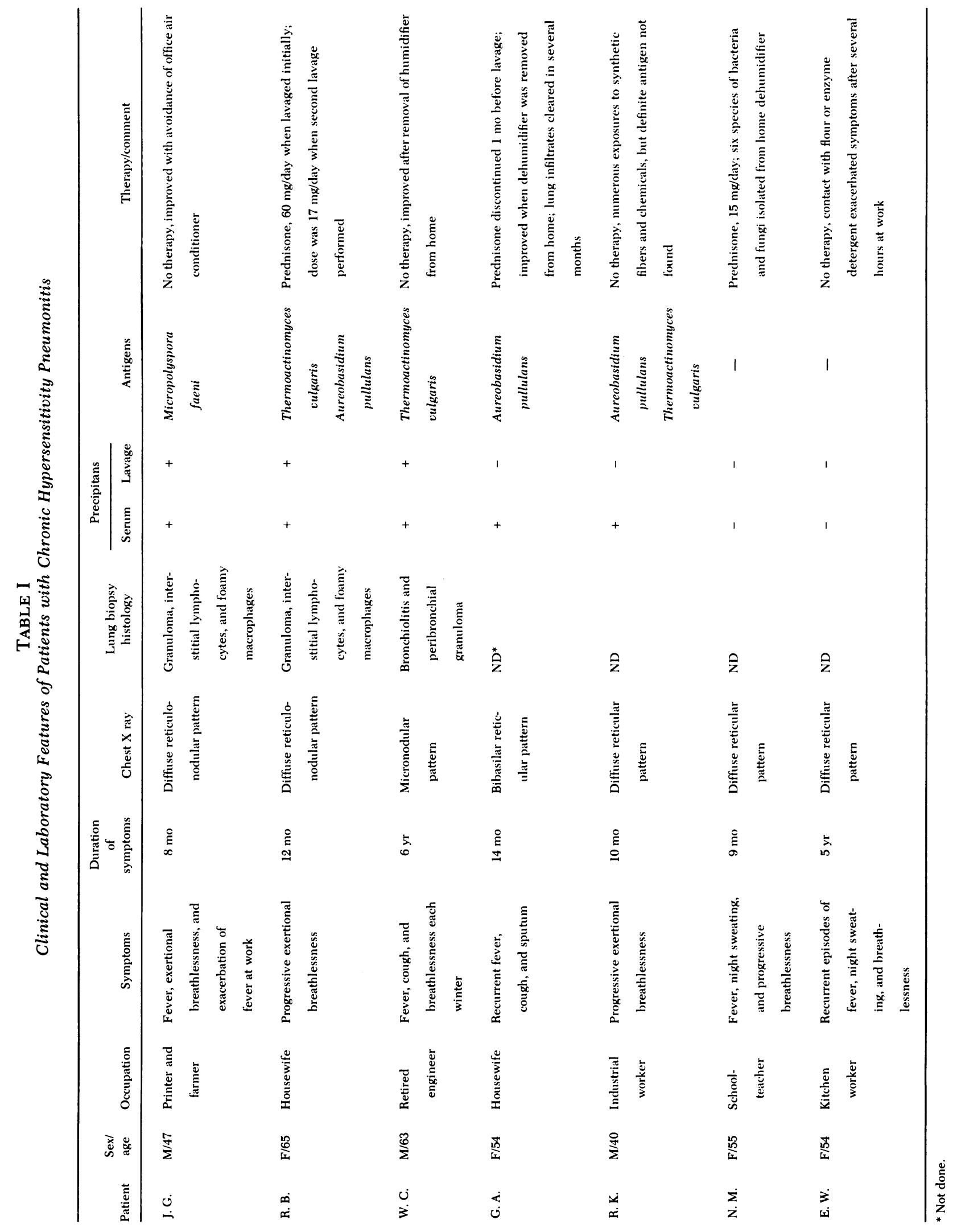


TABLE II

General Characteristics of Lavage Fluid from Patients with IPF and from Controls

\begin{tabular}{|c|c|c|c|c|c|c|}
\hline Groups & $\begin{array}{l}\text { Number } \\
\text { of } \\
\text { patients }\end{array}$ & $\begin{array}{c}\text { Recovery of } \\
\text { infused } \\
\text { lavage } \\
\text { fluid }\end{array}$ & $\begin{array}{l}\text { Total cells } \\
\text { recovered }\end{array}$ & $\begin{array}{c}\text { Cell } \\
\text { viability }\end{array}$ & $\begin{array}{l}\text { Concentration } \\
\text { of protein in } \\
\text { lavage fluid* }\end{array}$ & $\begin{array}{c}\text { Concentration } \\
\text { of albumin in } \\
\text { lavage fluid }\end{array}$ \\
\hline & & $\%$ & $\times 10^{7}$ & $\%$ & $m g / m l^{*}$ & $m g / m l$ \\
\hline $\begin{array}{l}\text { Control, } \\
\text { Nonsmokers }\end{array}$ & 11 & $\begin{array}{c}48.3 \pm 6.3 \S \\
(30-80)\end{array}$ & $\begin{array}{l}0.63 \pm 0.2^{\prime} \\
(0.1-1.1)\end{array}$ & $88.0 \pm 3.0$ & $\begin{array}{c}3.8 \pm 0.8 \\
(1.3-7.6)\end{array}$ & $\begin{array}{c}1.7 \pm 0.5 \\
(0.5-3.0)\end{array}$ \\
\hline Smokers & 21 & $\begin{array}{l}43.0 \pm 4.0 \\
(10-77)\end{array}$ & $\begin{array}{l}1.44 \pm 0.4 \\
(0.2-7.7)\end{array}$ & $82.2 \pm 3.5$ & $\begin{array}{c}2.5 \pm 0.3 \\
(0.7-5.2)\end{array}$ & $\begin{array}{c}1.0 \pm 0.1 \\
(0.3-1.9)\end{array}$ \\
\hline $\begin{array}{l}\text { IPF, } \\
\text { No therapy } \neq\end{array}$ & 7 & $\begin{array}{c}31.0 \pm 8.0 \\
(15-65)\end{array}$ & $\begin{array}{l}2.61 \pm 1.0^{\prime \prime} \\
(1.3-7.0)\end{array}$ & $90.7 \pm 2.3$ & $\begin{array}{c}3.9 \pm 0.9 \\
(1.6-8.1)\end{array}$ & $\begin{array}{c}1.2 \pm 0.4 \\
(0.3-2.8)\end{array}$ \\
\hline On therapy $\neq$ & 12 & $\begin{array}{c}41.0 \pm 4.2 \\
(20-74)\end{array}$ & $\begin{array}{l}1.33 \pm 0.4 \\
(0.3-3.6)\end{array}$ & $87.3 \pm 3.1$ & $\begin{array}{c}2.8 \pm 0.4 \\
(0.7-4.3)\end{array}$ & $\begin{array}{c}0.9 \pm 0.2 \\
(0.3-2.0)\end{array}$ \\
\hline Nonsmokers & 12 & $\begin{array}{l}41.7 \pm 4.3 \\
(15-74)\end{array}$ & $\begin{array}{l}1.85 \pm 0.6 \\
(0.2-8.0)\end{array}$ & $84.0 \pm 5.0$ & $\begin{array}{c}3.4 \pm 0.6 \\
(1.1-8.0)\end{array}$ & $\begin{array}{c}1.0 \pm 0.2 \\
(0.3-2.6)\end{array}$ \\
\hline Smokers & 7 & $\begin{array}{c}33.8 \pm 7.0 \\
(15-65)\end{array}$ & $\begin{array}{l}1.36 \pm 0.4 \\
(0.2-3.6)\end{array}$ & $87.4 \pm 3.2$ & $\begin{array}{c}2.9 \pm 0.8 \\
(0.8-7.5)\end{array}$ & $\begin{array}{c}1.1 \pm 0.4 \\
(0.2-2.8)\end{array}$ \\
\hline $\mathrm{CHP}$ & $7 * *$ & $\begin{array}{c}48.1 \pm 3.8 \\
(30-66)\end{array}$ & $\begin{array}{l}1.83 \pm 0.27 \\
(1.0-3.7)\end{array}$ & $92.2 \pm 2.1$ & $\begin{array}{c}15.2 \pm 2.29 \\
(7.0-26.0)\end{array}$ & $\begin{array}{c}2.8 \pm 0.5 \rrbracket \\
(0.8-6.3)\end{array}$ \\
\hline
\end{tabular}

* Broncho-alveolar lavage was concentrated to a $1.0-\mathrm{ml}$ volume.

\$ Includes nonsmokers and smokers.

$\S$ Mean \pm SEM, range for the group observed given in parentheses.

"The difference in total cells recovered in IPF (no therapy) and control (nonsmokers) was significantly different (Student's $t$ test, $P<0.05$ ).

I The concentration of protein and albumin in lavage fluid of patients with CHP was significantly greater than that in all other groups $(P<0.05$ all cases).

** 10 lavages in seven patients; repeat lavages after general clinical improvement, generally showed a decrease in total protein concentration (J. G. $23.0-8.2 \mathrm{mg} / \mathrm{ml}$; R. B. 26.0-8.9 mg/ml; W. C. $17.0-7.0 \mathrm{mg} / \mathrm{ml})$.

FN, Coulter Electronics, Hialeah, Fla.), viability (8) and differential counts. The latter were made from cytocentrifuge smears stained with Wright-Giemsa.

For patients with CHP, the relative proportions of bone marrow-derived (B) and thymus-derived (T) lymphocytes were determined in lavage and peripheral blood. Lymphocytes were separated from the respiratory cell pellet or from heparinized blood with a two-step procedure (9). First, mononuclear cells were banded by density gradient centrifugation with Hypaque-Ficoll (Pharmacia Fine Chemicals, Inc., Piscataway, N. J.) (10) and subsequently washed three times in Eagle's minimum essential medium (Grand Island Biological Co., Grand Island, N. Y.). Secondly, columns of Sephadex G-10 (Pharmacia Fine Chemicals, Inc.) were used to deplete the cell preparations of monocytes or alveolar macrophages $(11,12)$. For respiratory cells, a column of 10 ml Sephadex gel was equilibrated with Eagle's minimum essential medium containing $10 \%$ fetal calf serum, $10^{7}$ cells were washed into the column and the nonadherent cells were eluted with Eagle's minimum essential medium at room temperature. For blood cells the column was made with 30 $\mathrm{ml}$ of Sephadex and $10^{8}$ cells were used. This column method consistently yielded a 95-98\% pure population of lympho- cytes with viability of at least $95 \%$. The net recovery of total lymphocytes from the original cell pellet was $85.0 \pm 4.0 \%$. Comparison of the original cell pellet and the postcolumn purified lymphocytes showed no change in the relative proportion of $\mathrm{T}$ and $\mathrm{B}$ lymphocytes (12). The percentage of $\mathrm{T}$ lymphocytes were defined as those forming erythrocyte (E) rosettes with sheep red blood cells (SRBC) (13). The percentage of $B$ lymphocytes was defined as those forming rosettes with SRBC (E)-rabbit IgM-anti-SRBC antibody (A)-mouse serum complement (C) complexes (EAC rosettes) $(14,15)$. Details of these reagents and procedures have been described elsewhere (16).

Protein analysis. The supernate from the initial centrifugation was concentrated at $4^{\circ} \mathrm{C}$ to a final volume of $1.0 \mathrm{ml}$ with a combination of positive pressure ultrafiltration (Diaflo, UM-10 membrane, Amicon Corp., Scientific Sys. Div., Lexington, Mass.) and negative pressure dialysis. Quantitative measurements in this concentrated lavage included: total protein by the Lowry method (17); albumin and immunoglobins $\mathrm{G}$ and $\mathrm{M}$ by radial immunodiffusion in agar (Behring Diagnostics, American Hoechst, Somerville, N. J.); IgE with a radioimmunoabsorbent method (Pharmacia Laboratories Inc.); and hemolytic complement (C4 and C6 titers) $(18,19)$. 
Similar methods were used to quantitate serum protein values.

When initial studies of lavage fluid from patients with IPF indicated that approximately $25 \%$ of the total IgA was monomeric (7S) and $75 \%$ was polymeric (11S), it was apparent that radial immunodiffusion precipitation, using a single IgA standard protein, would not accurately quantitate the two populations of IgA present. To obviate this problem, 0.3 $\mathrm{ml}$ of the concentrated lavage fluid was sedimented in $10-40 \%$ linear sucrose density gradients (20); the $7 S$ and $11 S$ IgA fractions were selectively pooled, dialyzed to remove residual sucrose, and quantitated using human monomeric $\operatorname{IgA}$ and secretory IgA standards, respectively (7). The IIS component was identified as secretory IgA by size, immunoreactivity with secretory component antiserum and the presence of J-chain. Total IgA was calculated from the sum of the monomeric and secretory values and extrapolated to a $1-\mathrm{ml}$ volume.

Specific precipitating antibodies against a variety of antigens ${ }^{3}$ known to cause CHP were assayed by Ouchterlony radial immunodiffusion in the laboratories of $\mathrm{F}$. Wenzel at the Marshfield Clinic, Marshfield, Wis.; similar assays were done in our laboratories using antigens obtained from Hollister-Stier Labs, Spokane, Wash. (lot 089701) and Greer Lalbs, Lenoir, N. C. (lot K5B-8).

Statistical comparisons. Group data are expressed as a mean \pm SEM; mean values were compared with Student's $t$ test (two-tailed) analysis.

\section{RESULTS}

61 lavage procedures were performed in 58 patients (19 IPF, 7 CHP, and 32 controls). Lavage required $5-10 \mathrm{~min}$ to complete. It was well tolerated by patients and did not add to the discomfort or morbidity of bronchoscopy.

Since prior studies have demonstrated in normal subjects that cigarette smoking can significantly influence the recovery of respiratory cells $(7,21-23)$, results from patients with IPF are also segregated as to smoking status (Table II). The percentage of lavage fluid recovered from patients with IPF on no therapy tended to be less than from other groups, particularly the nonsmoking controls $(P=0.08)$ (Table II).

Analysis of cells in IPF lavage. The total number of cells recovered from lavage of patients with untreated IPF was significantly greater than from nonsmoking controls $(P<0.05)$ but not significantly different than from smoker controls $(P>0.1)$. Recovery of cells from IPF patients on therapy appeared to be less than from those untreated, but this difference was not significant $(P>0.1)$. Smoking status did not influence the total number of cells recovered from patients with IPF. The viability of lavage fluid cells was similar between all groups (Table II).

Of patients with IPF (nontreated and treated), $73 \%$

${ }^{3}$ Antigens used included: Micropolyspora faeni, Thermoactinomyces vulgaris, T. viridis, T. sacchari, Aspergillus fumigatus, Asp. sydowi, Asp. glaucus, Asp. niger, pigeon sera, pigeon droppings, Cryptostroma corticale, and Aureobasidium pullulans.

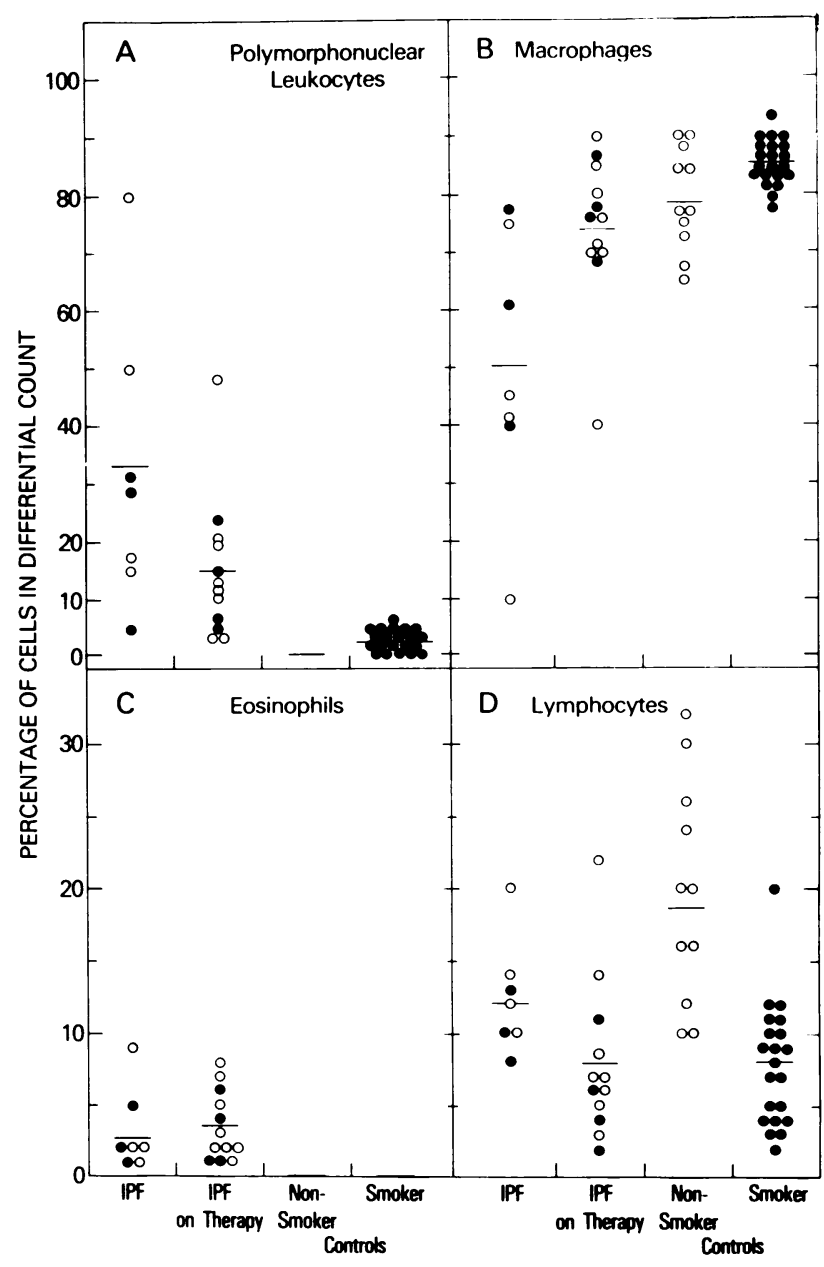

FIGURE 1 Percentage of cells identified in the differential count of lavage fluid is shown for patients with untreated IPF, patients with treated IPF, nonsmoker controls, and smoker controls. A horizontal line represents the mean for the group. Nonsmokers $(O)$ and smokers $(0)$ are designated. In nonsmoking controls, there were no PMNs found; in nonsmoking controls and smoking controls no eosinophils were present.

had a greater percentage of polymorphonuclear leukocytes $(\mathrm{PMN})$ in their lavage differential count than did controls (Fig. 1A). Although there was a broad range which overlapped, the mean percentage of PMNs in treated IPF $(14.0 \pm 4.0 \%)$ was significantly lower $(P<0.05)$ than that in untreated IPF $(33.0 \pm 8.0 \%)$. In the smoking controls, PMNs were infrequent $(3.0 \pm 0.4 \%)$ and in the nonsmoking controls they were absent. There was no significant difference in the percentage of PMNs in lavage from IPF nonsmokers and smokers.

The percentage of macrophages (Fig. 1B) found in control groups and for treated IPF patients were not significantly different. The lower percentage of macrophages in the untreated IPF group $(P<0.05)$ was 


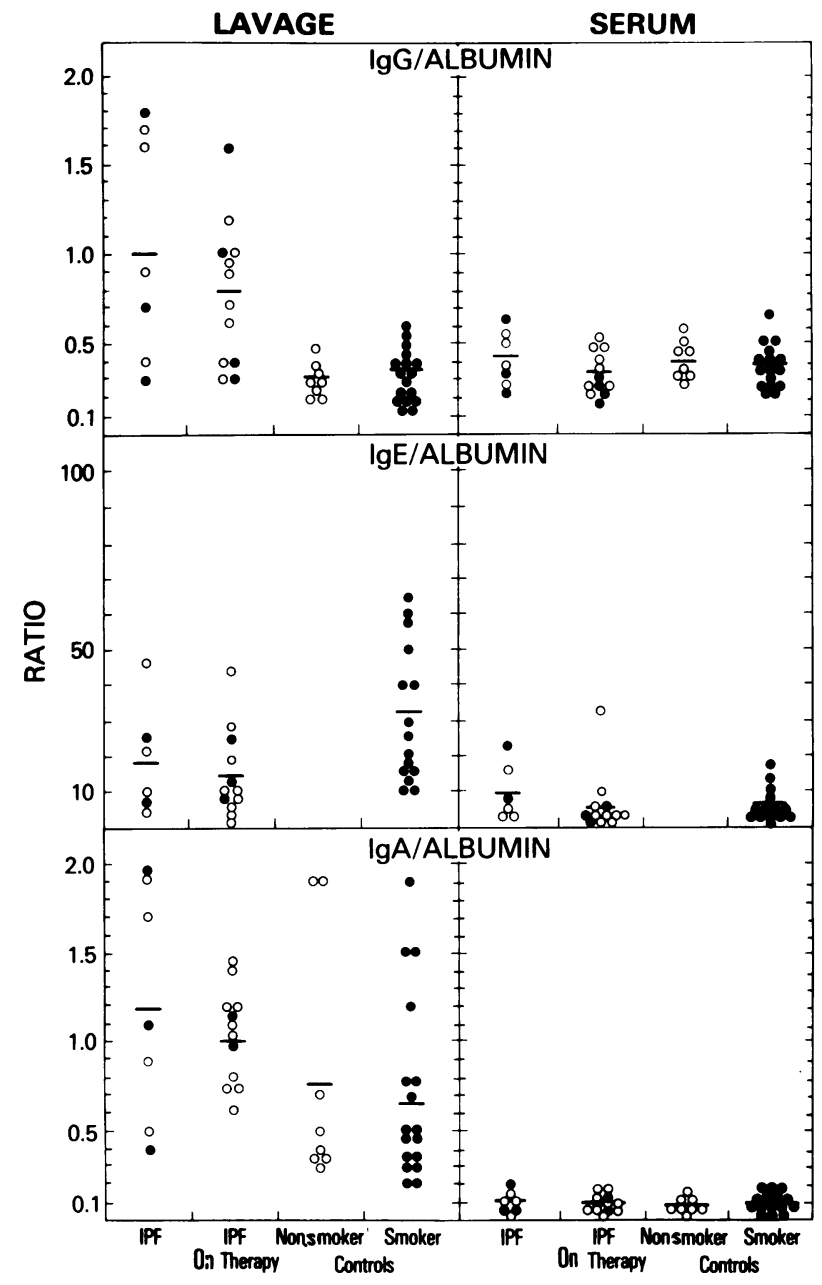

FIGURE 2 A comparison of immunoglobulin levels in lavage fluid and serum is shown for patients with untreated IPF, IPF patients under treatment, nonsmoker controls, and smoker controls. The immunoglobulin data are presented as a ratio to the respective albumin level in the same sample (Results). A horizontal line denotes the mean for the group. Nonsmokers (O), smokers $(O)$ are designated. IgG/albumin and IgA/albumin ratios are expressed as milligram per milligram. IgE/albumin ratios are in nanogram per milligram; these levels are not available for the nonsmoker controls.

probably secondary to the relative increase in PMNs in these patients.

The percentage of eosinophils (Fig. IC) in the IPF cell differentials was significantly higher $(P<0.001)$ than for control subjects in whom eosinophils were not detected. Eosinophils persisted in IPF despite anti-inflammatory therapy. The number of eosinophils in the peripheral blood of these patients was not elevated except for mildly increased absolute circulating eosinophil counts in 3 of the 19 IPF patients (718 \pm 46 eosinophils $/ \mathrm{mm}^{3}$ for the 3 patients).

The percentage of lymphocytes in IPF lavage fluid
(Fig. 1D) was neither increased compared with controls nor altered appreciably by therapy. Erythrocytes in the respiratory cell pellets generally were less than $3 \%$.

Protein analysis in IPF. Quantitative analysis of proteins recovered from the lower respiratory tract of human subjects is difficult, since the broncho-alveolar bathing fluid can only be recovered by "washing" it out. Two approaches can be used to obviate this problem.

First, a standardized lavage procedure $(100 \mathrm{ml}$ infusion) was used. Although a variable amount of lavage fluid was recovered from individual patients, the mean volumes recovered from the different patient groups were not significantly different (Tab)le II), and quantitative measurements of lavage proteins can be expressed as units per milliliter of concentrated lavage fluid. For example, there were no significant differences between the total protein concentrations found in lavage fluid of all groups analyzed (Table II).

Secondly, lavage protein values can be expressed in relation to a reference protein in the lavage. Albumin was chosen as this reference standard (24) because it is not synthesized in the lung and its presence in broncho-alveolar fluid reflects transudation from the intravascular compartment. In addition, the relative amounts of albumin in lavage analyses were not significantly different in the various patient groups (Table II). Likewise, albumin values in serum were comparable for the various groups (data not shown). The ratio of a specific protein (milligram per milliliter) to albumin (milligram per milliliter) in lavage fluid could be compared directly to the ratio of these proteins in serum. Thus, the ratio of a specific protein to albumin in lavage should be the same as that in serum if proteins are present in the lower respiratory tract secondary to transudation from serum. A high ratio of a specific protein to albumin in lavage was taken as evidence of a relative increase of that protein in the lower respiratory tract compared to serum. This second method was found to be much more useful, and all of the data are presented in this manner. The mean concentrations of each protein (amount per milliliter) in lavage can be calculated from the protein to albumin ratios by using the mean albumin concentrations for each group (Table II).

Serum IgG to albumin ratios were similar in all patients; the individual ratios were always less than 0.65 (Fig. 2). In control subjects, lavage IgG/albumin ratios, likewise, were always less than 0.65 . In IPF patients, however, lavage IgG/albumin ratios were greater than 0.65 in $63 \%$ ( 12 of 19) patients. The mean ratios for lavage fluid in untreated IPF (1.06 $\pm 0.24)$ and treated IPF $(0.78 \pm 0.12)$ were significantly higher than those for controls $(P<0.01$ all compari- 
sons). The elevated lavage IgG/albumin levels in IPF were not dependent upon the smoking status of the patient (Fig. 2).

In general, patients on treatment for IPF had lower ratios of lavage $\mathrm{IgE} / \mathrm{albumin}$ than smoker controls $(P<0.025)$ despite considerable variation in the control values. $50 \%$ of the untreated IPF patients also had lower lavage IgE/albumin values than controls, but the mean for this group was not significantly lower than controls $(P>0.1)$. Unfortunately, data were not available for nonsmoker controls, but results obtained in nonsmoking volunteers demonstrate lavage IgE/albumin values comparable to those found in the smoker controls (7). Serum levels of IgE/albumin were similar in all groups. Lavage IgE/albumin for some IPF patients tended to be higher than that in serum; for controls the lavage values were significantly higher than serum values $(P<0.001)$ (Fig. 2). One subject (A. R.) in the untreated IPF group was excluded because of a history of atopic disease. Interestingly, his serum IgE level was $3,000 \mathrm{ng} / \mathrm{ml}$ ( $\operatorname{IgE}$ albumin ratio of 100) while his lavage $\mathrm{IgE}$ was $24 \mathrm{ng} / \mathrm{ml}(\mathrm{IgE} /$ albumin ratio of 9 ).

IgA/albumin values in the serum of all patients were in a narrow range (ratio 0.05-0.2 in all cases) while the IgA/albumin values in lavage fell broadly over a 10-fold range (0.2-2.0). As expected in all groups, lavage IgA/albumin was significantly higher than serum values, but there were no significant differences in lavage values between groups (Fig. 2). In controls, $9 \%$ of lavage IgA was monomeric (7) while in IPF $25-30 \%$ of lavage IgA was in the monomeric form. Interestingly, the use of IgA/albumin ratios to analyze IPF serum values obscured the fact that serum IgA levels were increased $(>3.5 \mathrm{mg} / \mathrm{ml})$ in $71 \%$ of the untreated IPF group but only in $25 \%$ of the treated IPF patients.

With double-diffusion immunoprecipitation analysis of lavage fluid, IgM was detected in only $15 \%$ of specimens from IPF patients (sensitivity of the IgM assay was $0.1 \mathrm{mg} / \mathrm{ml}$ ). Likewise, this immunoglobulin was found in approximately $5 \%$ of control specimens (7). Serum IgM values were within the normal range for our laboratory $(0.9-1.7 \mathrm{mg} / \mathrm{ml})$ for IPF patients on no therapy $(1.5 \pm 0.3 \mathrm{mg} / \mathrm{ml})$ and for those on treatment $(1.7 \pm 0.3 \mathrm{mg} / \mathrm{ml})$. Serum values for control nonsmokers $(1.8 \pm 0.2 \mathrm{mg} / \mathrm{ml})$ and smokers $(1.5 \pm 0.3 \mathrm{mg} / \mathrm{ml})$ were comparable.

C4 hemolytic complement titers in lavage, expressed as a ratio to albumin, were the same for the IPF groups and for smoker controls (Fig. 3). However, mean ratios in lavage fluid were significantly lower $(P<0.01)$ than corresponding serum ratios for the IPF group on therapy and for smoker controls. Likewise, mean lavage values of C6/albumin were comparable in all groups, but were also significantly lower than respective serum

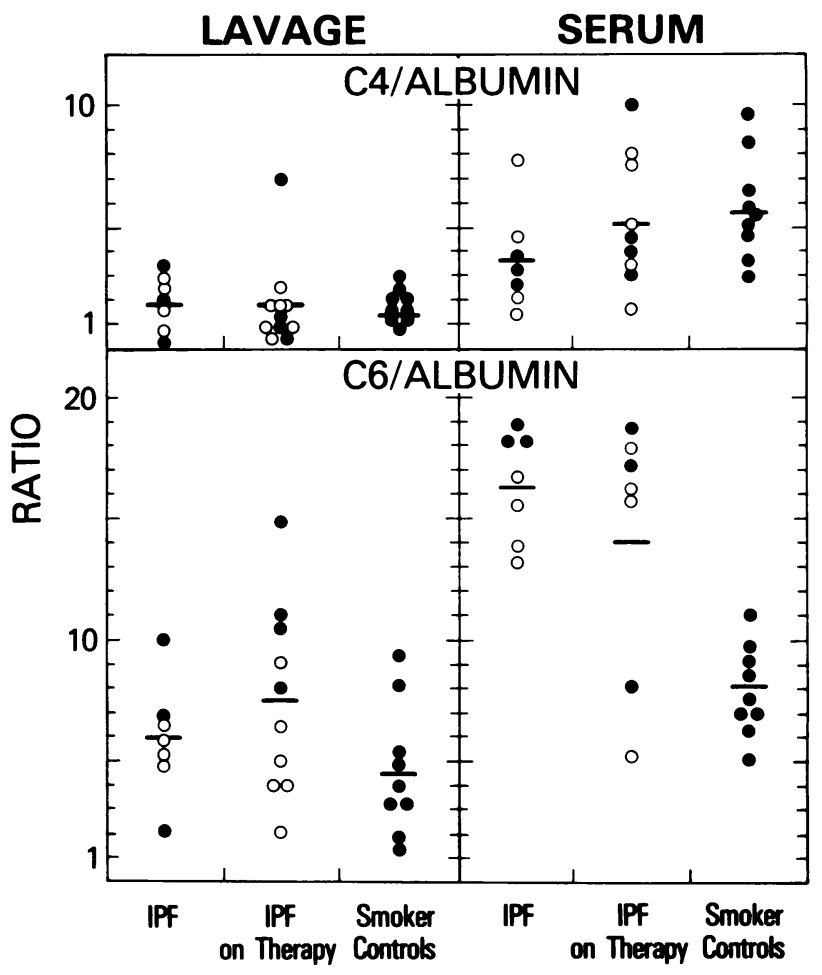

FiguRE 3 A comparison of complement levels in lavage fluid and serum is shown for patients with untreated IPF, patients with IPF under treatment and smoker controls. The mean value for each group is given by a horizontal bar. Nonsmokers (O), smokers (O) are designated. The C4 data are calculated as $10^{-3}$ hemolytic titer per milligram albumin; the C6 data are calculated as hemolytic titer per milligram albumin.

ratios $(P<0.01)$. In addition, mean serum $\mathrm{C6} / \mathrm{albumin}$ values in the IPF groups were significantly greater $(P<0.01)$ than those of smoker controls.

Cell and protein analysis in CHP. The mean recovery of the lavage fluid from patients with CHP (about 48\%) was generally better than in the IPF groups but the total cell recovery was comparable (Table II). PMNs represented an average of $8.5 \%$ of respiratory cells in CHP (Fig. 4). (A higher percentage was noted for patient $\mathrm{R}$. K. and for the second analysis in R. B. and W. C.; both of these latter patients had an episode of bronchitis 3-4 wk before the second lavage study.) Eosinophils represented $0.5-2 \%$ of all respiratory cells of patients with CHP while approximately $29 \%$ of the lavage cells were alveolar macrophages with distinctive foamy macrophages constituting about $10 \%$ of the macrophage population.

In striking contrast to patients with IPF and to controls, lymphocytes accounted for approximately $62 \%$ of the lavage cells in CHP. When lavage lymphocytes were characterized by sheep erythrocyte ( $\mathrm{T}$ cells) and complement (B cells) rosette techniques (Fig. 4), the 

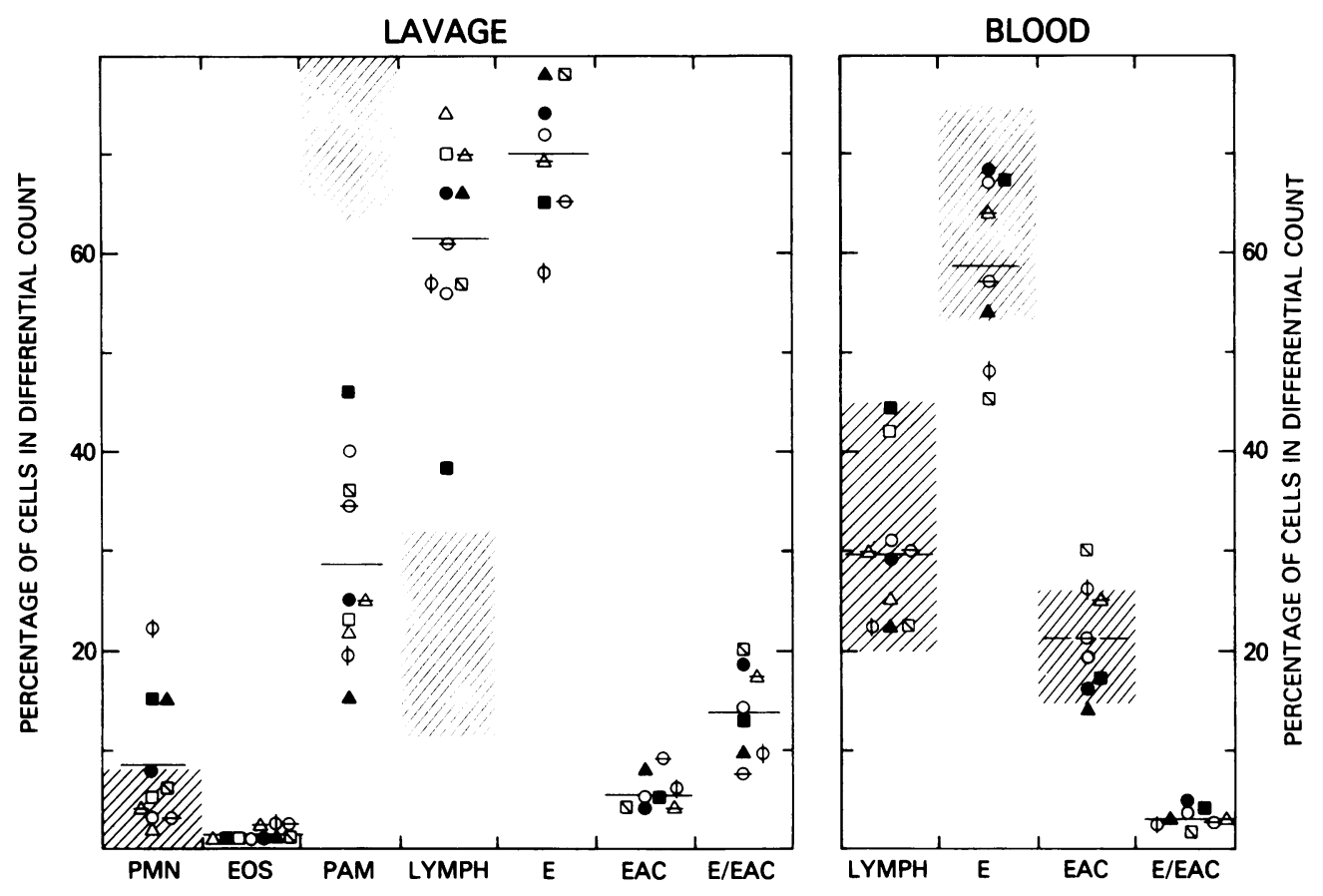

FIGURE 4 Percentage of cells identified in the differential count of lavage fluid of seven patients with chronic hypersensitivity pneumonitis. There were 10 lavages done in 7 patients. A single symbol is used for each patient described in Table I: J. G. first lavage (O); J. G. lavage 7 mo later

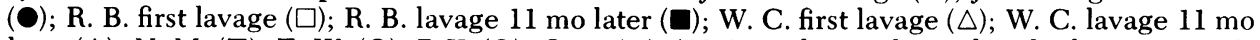
later $(\Delta)$; N. M. $(\nabla)$; E. W. $(\ominus)$; R K. (Ф); G. A. (A). (PMN, polymorphonuclear leukocytes; EOS, eosinophils; PAM, pulmonary alveolar macrophages; LYMPH, lymphocytes; E, T lymphocytes; EAC, B lymphocytes; E/EAC, ratio of T to B lymphocytes.) A horizontal line represents a mean for the group. For the lavage data, shaded areas represent the range of values found in lavage of controls (nonsmokers and smokers) given in Fig. 1. In normals, no eosinophils are found in lavage and the range for macrophages is $63-92 \%$. For the blood data, the shaded areas represent the control values established for peripheral blood lymphocytes from young adults $(n=15)$. All of the data in this figure is expressed as a percentage of total cells in a differential count except for the E/EAC column (lavage and blood) which is presented as the ratio of percentage $\mathrm{E}$ to percentage EAC.

vast majority of respiratory lymphocytes were identified as T lymphocytes (mean $70 \pm 2.5 \%$ ) and only about $6 \%$ could be identified as B lymphocytes. The mean ratio of E/EAC (T/B cells) was about 14. Approximately $24 \%$ of the respiratory lymphocytes were unidentified with our immune reagents and were considered null cells.

In contrast, values for peripheral blood leukocytes and lymphocytes were within the normal range in all patients with CHP. Analysis of the blood lymphocytes demonstrated that $59 \%$ were $\mathrm{T}$ cells and $21 \%$ were $\mathrm{B}$ cells, giving a blood $\mathrm{T}$ to $\mathrm{B}$ mean ratio of $3: 1$. The percentage of $T$ lymphocytes in lavage was significantly greater $(P<0.025)$ than in blood and the percentage of $\mathrm{B}$ lymphocytes in lavage was significantly less $(P<0.005)$. The resulting $\mathrm{T}$ to $\mathrm{B}$ ratios in lavage compared with those in blood were also significantly different $(P<0.005)$.

The mean total protein concentration present in the concentrated lavage fluid from these patients (15.2 $\pm 2.2 \mathrm{mg} / \mathrm{ml}$ ) was significantly higher than that found in IPF groups or controls $(P<0.01)$ (Table II). This was not due simply to more transudation of serum, since the ratio of albumin to total protein in $\mathrm{CHP}$ (mean $0.14 \pm 0.02)$ was much less than in IPF $(0.32$ $\pm 0.03)$ or controls $(0.44 \pm 0.07)(P<0.01$ for all comparisons). Repeat lavages in three CHP patients, done at times when there had been general clinical improvement, yielded less total protein (Table II).

Part of the excess broncho-alveolar protein in CHP was IgG. With the exception of the second analysis of R. B., the ratios of lavage IgG/albumin were $\geq 1.1$ in all cases of CHP. These ratios were higher than those found in $75 \%$ of the IPF patients and higher than any controls (Fig. 5 vs. Fig. 2). In contrast, the corresponding serum ratios in CHP (mean $0.42 \pm 0.03$ ) were similar to IPF and controls. IgG-rich fractions recovered from sucrose gradient fractionation of lavage 
and serum of patients J. G. and R. B. contained precipitating antibody to thermophylic actinomycetes ( $\boldsymbol{M}$. faeni) antigens when assayed by double-diffusion immunoprecipitation in agar.

IgM was measurable in all lavage specimens in CHP; its mere detection made it unusual in comparison with IPF (15\% had lavage IgM) or controls (5\% had lavage $\operatorname{IgM}$ ). The IgM/albumin levels in lavage vs. serum (Fig. 5) indicated a proportionally greater amount in the bronchoalveolar fluid than in serum. No precipitating antibodies were detected in lavage or serum IgM fractions recovered from sucrose gradients.

IgE/albumin levels in CHP lavage were higher than those found in serum. The lavage and serum ratios, however, were normal compared to the smoker controls (Fig. 5 vs. Fig. 2). Total IgA/albumin in CHP lavage was elevated compared with serum but was similar to controls. As found in IPF and controls, C4/albumin and C6/albumin levels were lower in CHP lavage fluid as compared with serum.

\section{DISCUSSION}

Limited lavage of the lower respiratory tract is a simple extension of routine fiber-optic bronchoscopy. While routine measurements, such as chest films and pulmonary function studies, monitor general lung function, analysis of broncho-alveolar lavage fluid is a direct attempt to evaluate specific mechanisms which may contribute to the continued activity of lung disease. Quantitation of cells and proteins in lavage of patients with IPF and CHP has demonstrated that the epithelial surface of the lower respiratory tract is involved in inflammatory and immunologic reactions that would not be suspected from analysis of blood alone. In addition, comparison of lavage cells and immunoglobulins from IPF and CHP show a number of similarities and differences which may be important in understanding these disorders.

Analysis of the lavage fluid from patients with IPF indicates that these patients have a local inflammatory process which was not seen in controls. How the presence of polymorphonuclear leukocytes relates to the fibrotic process is not known, but these studies suggest that when patients with IPF are treated, this inflammatory response tends to diminish.

In addition to the local accumulation of PMNs, the lower respiratory tract in IPF has a striking increase in IgG compared with serum IgG and with control lavage IgG. Since the IgG/albumin levels in the lavage fluid of these patients are significantly higher than their serum IgG/albumin levels, it is unlikely that the elevated IgG is secondary to transudation resulting from the inflammatory process. It is probable that in IPF there is local pulmonary production of $\operatorname{IgG}(25,26)$
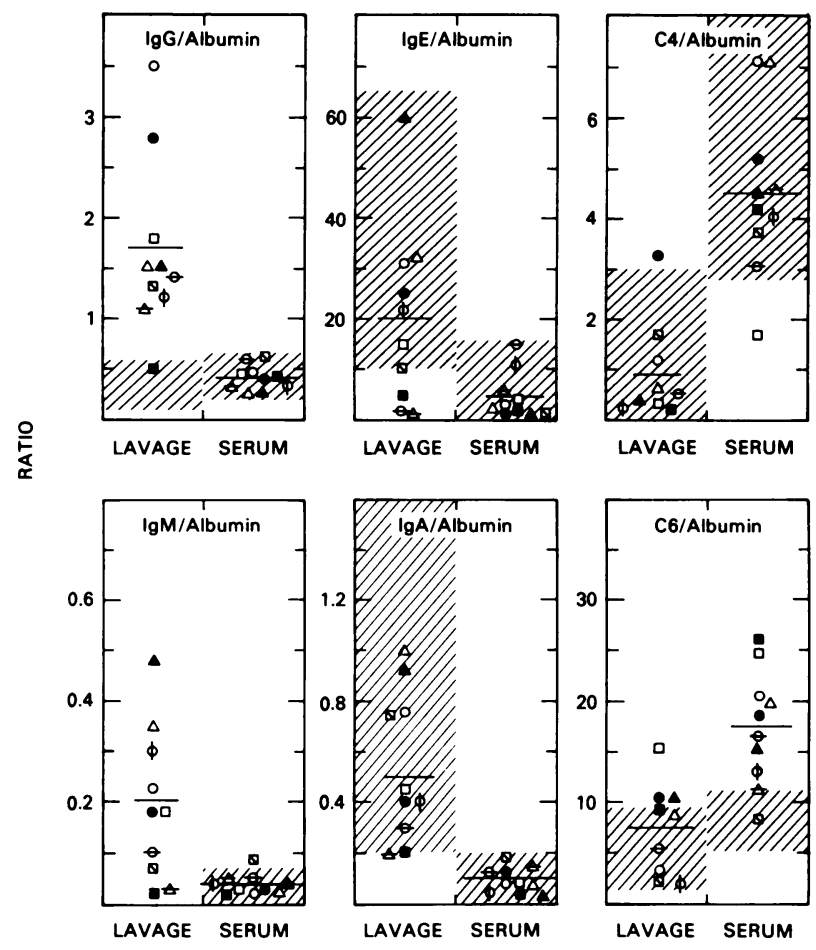

FIGURE 5 Quantitation of proteins in broncho-alveolar lavage and serum from patients with chronic hypersensitivity pneumonitis. The symbols for the patients are as in Fig. 4: J. G. first lavage $(O)$; J. G. lavage 7 mo later $(\mathbf{O})$; R. B. first lavage $(\square)$; R. B. lavage 11 mo later $(\square)$; W. C. first lavage $(\triangle)$; W. C. lavage 11 mo later $(\Delta)$; N. M. $(\Delta)$; E. W. $(\ominus)$; R. K. (D); G. A. (A). The immunoglobulin data (lavage and serum) are presented as a ratio to the respective albumin level in the same sample: IgG/albumin (milligrams per milligram), IgE/albumin (nanograms per milligram), IgM/albumin (milligrams per milligram), IgA/albumin (milligrams per milligram). C4 data are presented as $10^{-3}$ hemolytic titer per milligram albumin; C6 data are presented as hemolytic titer per milligram albumin. Shaded areas are the range of values for control (nonsmokers and smokers) given in Fig. 2 and 3. For control lavage IgM/albumin is $<0.01$ and, IgA/albumin is 0.3 to 1.8 . For control blood, C4/albumin is $2.8-9.8$.

and/or the mechanisms of IgG catabolism or removal are faulty. It is thus possible that part of the pathogenesis of IPF is secondary to IgG antibody being formed in the lung parenchyma in response to as yet unidentified antigen(s) resulting in local antibodyantigen complexes.

In CHP, the local accumulation of IgG is even more impressive. This finding is consistent with the concept that the pathogenesis of hypersensitivity pneumonitis is associated with a type III immune reaction in lung (3). In accord with this concept, two of the CHP patients (J.G. and R.B.) had broncho-alveolar IgG precipitins against thermophylic actinomycetes antigens. The lavage fluid from the CHP patients also contained significant quantities of IgM (compared to 
serum) further emphasizing the possible role of humoral immunity in this disease.

While the elevated levels of respiratory IgG in IPF and IgG and IgM in CHP suggest local type III immune reactions, both $I P F$ and CHP patients also had eosinophils present in their lavage fluid. This finding is interesting in several respects: $(a)$ in general, patients with IPF and CHP did not have blood eosinophilia; (b) controls had no eosinophils in their lavage fluid; and $(c)$ therapy with corticosteroids did not influence the local eosinophil accumulation. Although these findings suggest that a localized allergic reaction might be occurring in the lung parenchyma of these patients, the generally low levels of $\mathrm{IgE} / \mathrm{albumin}$ in lavage fluid from patients with IPF and CHP argue against the classic type type I reagin-mediated lung reaction being important (3, 27-29). Thus disease mechanisms in IPF and CHP are probably not associated with combined type I and III immune reactions found in a disorder such as allergic bronchopulmonary aspergillosis (3).

In both IPF and CHP, the total IgA/albumin levels in lavage were normal. However, in both disorders, the relative proportion of monomeric IgA in the bronchoalveolar fluid was increased compared with controls. The reason for this finding is not clear although it is possible that the monomeric IgA represents transudation from the intravascular compartment. Alternatively, inflammation enhanced proteolytic degradation of locally produced secretory IgA could explain this finding. Irrespective of the cause of increased monomeric IgA in the lower respiratory tract in IPF and CHP, neither disorder appears to be associated with a local abnormality of secretory IgA.

There is no direct evidence in these studies that either IPF of CHP are associated with local complement-mediated reactions. Although C4/albumin levels in the broncho-alveolar fluid tended to be lower than serum (Figs. 3, 5), there was no difference between IPF, CHP, or controls. The lower values of complement activity in all lavage analyses may be more apparent than biologically significant. Although complement titers were promptly assayed, its activity is known to be labile and undoubtedly some activity is lost in the lung washout and concentrating procedures. The elevated levels of serum C6 in IPF and CHP may be due to $\mathrm{C} 6$ acting as an acute phase reactant in these patients.

While the eosinophils, IgG, IgA, IgE, C4, and C6 levels in the lavage fluid of IPF an CHP are quite similar, analysis of other cellular and protein contents of the broncho-alveolar fluid in CHP provides a striking contrast to that in IPF and controls. Lavage fluid of these patients contained alveolar macrophages with foamy cytoplasm which are considered to be characteristic of the histology found in the hypersensitivity lung disorders (4). Such cells were not noted in IPF or controls. In 10 lavage analyses from 7 patients with CHP, the average percentage of broncho-alveolar lymphocytes was $62 \%$ compared to about $10 \%$ in IPF (treated and untreated), $8 \%$ in smoker controls and $18 \%$ in nonsmoker controls. Even though all patients with CHP had elevated broncho-alveolar IgG and IgM, and two had IgG precipitating antibodies in the lavage fluid against a specific fungal antigen, the exaggerated broncho-alveolar lymphocyte response in CHP is not one of B lymphocytes, as might be expected, but rather one of $\mathrm{T}$ lymphocytes. This finding suggests, as in experimental animal models of hypersensitivity pneumonitis $(5,6)$, that cell-mediated mechanisms may also be important in CHP. Thus, in human hypersensitivity disease, there is preliminary evidence of localized humoral and cellular immunity in the pathogenesis of the disorder. The consequences of this T-cell accumulation in CHP are unknown, although it is possible that activation of these cells to liberate local mediators may provide a stimulus for granuloma formation, eosinophil accumulation and/or cell injury.

Based on the high ratio of $\mathrm{T} / \mathrm{B}$ lymphocytes found in CHP lavage fluid compared to blood (Fig. 4), T cells appeared to be sequestered in affected pulmonary tissue. This finding was even more striking when compared to the recent studies of Daniele et al. (30) who noted that in normal humans, broncho-alveolar $\mathrm{T} / \mathrm{B}$ ratios were the same as in blood. These lymphocyte results together with the immunoglobulin data in both IPF and CHP suggest that the lung can function partially independent of systemic humoral- and cellmediated immune systems.

Lung biopsies were available from 17 of the IPF patients and from 3 of the CHP patients. In most, the biopsy was done some months before the lavage study. Nevertheless, in 17 of the 20 patients in whom biopsy was performed, the cells in the alveoli and small airways were similar and in same relative proportions as found in cell differential counts obtained from broncho-alveolar lavage. Thus, our findings corroborate those of Davis et al. (31) who found cell content of lavage to be similar to alveolar cellular content in patients with interstitial pneumonitis.

It is doubtful that analysis of broncho-alveolar lavage fluid can ever give as much information about parenchymal pathology in lung disease as can an open lung biopsy specimen. However, whereas open lung biopsy is usually done only once to establish a diagnosis, broncho-alveolar lavage does permit periodic assessment of the disease process with little risk and discomfort to the patient. Thus, analysis of lavage fluid from patients with fibrotic lung disease adds another dimension to evaluation of these disorders. Lavage fluid represents the epithelial milieu of the lung parenchyma and therefore gives further insight into local phenomena causing the lung disease. It may prove useful in following the effect of therapy on 
these disorders. Most importantly, the differences between the cellular analyses in CHP compared to IPF and controls indicate that broncho-alveolar lavage could be useful diagnostically in categorizing patients with pulmonary fibrosis even when specific organic antigens cannot be readily identified.

\section{ACKNOWLEDGMENTS}

We thank Doctors Norton Elson, Joel Moss, and Edward Stool who did the lavage procedures; Dr. Fritz Wenzel of the Marshfield Clinic for serologic studies; Dr. Anthony S. Fauci and Dr. Charles H. Kirkpatrick for their advice; Ms. Thelma Gaither, Ms. Patricia A. Johnson, and Mr. Geoffrey Hudson for technical help; Dr. David W. Alling for help with the statistical analysis; and Mrs. Nancy Wyne, Mrs. Joy Barchers, and Mrs. Kristen Cook for their editorial assistance.

\section{REFERENCES}

1. Liebow, A. A., and C. B. Carrington, 1968. The interstitial pneumonias. In Frontiers of Pulmonary Radiology. M. Simon, E. J. Potchen, and M. Lemay, editors. Grune \& Stratton, Inc. New York. 102-141.

2. Fulmer, J. D., and R. G. Crystal. 1976. The biochemical basis of pulmonary function. In The Biochemical Basis of Pulmonary Function. R. G. Crystal, editor. Marcel Dekker, Inc., New York. 419-466.

3. McCombs, R. P. 1972. Diseases due to immunologic reactions in the lungs. N. Engl. J. Med. 286: 1186-1194, 1245-1252.

4. Fink, J. N., 1976. Hypersensitivity pneumonitis. In Immunologic and Infectious Reactions in the Lung. C. H. Kirkpatrick, and H. Y. Reynolds, editors. Marcel Dekker, Inc., New York 229-241.

5. Hensley, G. T., J. N. Fink, and J. J. Barboriak. 1974. Hypersensitivity pneumonitis in the monkey. Arch. Pathol. 97: 33-38.

6. Moore, V. L., G. T. Hensley, and J. N. Fink. 1975. An animal model of hypersensitivity pneumonitis in the rabbit. J. Clin. Invest. 56: 937-944.

7. Reynolds, H. Y., and H. H. Newball. 1974. Analysis of proteins and respiratory cells obtained from human lungs by bronchial lavage. J. Lab. Clin. Med. 84: 559573.

8. Hanks, J. H., and J. H. Wallace. 1958. Determination of cell viability. Proc. Soc. Exp. Biol. Med. 98: 188- 192.

9. Kazmierowski, J. A., A. S. Fauci, and H. Y. Reynolds. 1976. Characterization of lymphocytes in bronchial lavage fluid from monkeys. J. Immunol. 116: 615-618.

10. Böyum, A. 1968. Isolation of mononuclear cells and granulocytes from human blood. Scand.J. Clin. Invest. 21 (Suppl. 97): 77-89.

11. Ly, I. A., and R. I. Mishell. 1974. Separation of mouse spleen cells by passage through columns of Sephadex G-10. J. Immunol. Methods. 5: 239-247.

12. Schwartz, R. H., A. R. Bianco, B. S. Handwerger, and C. R. Kahn. 1975. Demonstration that monocytes rather than lymphocytes are the insulin-binding cells in preparations of human blood mononuclear leukocytes; implications for studies of insulin-resistant states in man. Proc. Natl. Acad. Sci. U. S. A. 72: 474-478.

13. Weiner, M. S., C. Bianco, and V. Nussenzweig. 1973. Enhanced binding of neuraminidase-treated sheep erythrocytes to human $\mathrm{T}$ lymphocytes. Blood. 42: 939-946.

14. Bianco, C., R. Patrick, and V. Nussenzweig. 1970. A population of lymphocytes bearing a membrane receptor for antigen-antibody-complement complexes. I. separation and characterization. J. Exp. Med. 1:32: $702-720$.

15. Frank, M. M., and T. Gaither. 1970. The effect of temperature on the reactivity of guinea pig complement with $\gamma \mathrm{G}$ and $\gamma \mathbf{M}$ haemolytic antibodies. Immunology. 19: $967-974$.

16. Reynolds, H. Y., J. P. Atkinson, H. H. Newball, and M. M. Frank. 1975. Receptors for immunoglobulin and complement on human alveolar macrophages. J. Immunol. 114: 1813-1819.

17. Lowry, O. H., N. J. Rosebrough, A. L. Farr, and R. Randall. 1951. Protein measurement with the Folin phenol reagent. J. Biol. Chem. 19:3: 265-275.

18. Gaither, T. A., D. W. Alling, and M. M. Frank. 1974. A new one step method for the functional assay of the fourth component $\left(\mathbf{C}_{4}\right)$ of human and guinea pig complement. J. Immunol. 113: 574-583.

19. May, J. E. and M. M. Frank. 1972. Complement-mediated tissue damage: contribution of the classical and alternate complement pathways in the Forssman reaction. $J$. Immunol. 108: 1517-1525.

20. Reynolds, H. Y., and J. S. Johnson. 1971. Structural units of canine serum and secretory immunoglobulin A. Biochemistry. 10: 2821-2827.

21. Harris, J. O., E. W. Swenson, and J. E. Johnson, III. 1970. Human alveolar macrophages: comparison of phagocytic ability, glucose utilization, and ultrastructure in smokers and nonsmokers. J. Clin. Invest. 49: 2086-2096.

22. Sharp, P. M., G. A. Warr, and R. R. Martin. 1973. Effects of smoking on bronchial immunoglobulins. Clin. Res. 21: 672. (Abstr.)

23. Cantrell, E. T., G. A. Warr, D. L. Busbee, and R. R. Martin. 1973. Induction of aryl hydrocarbon hydroxylase in human pulmonary alveolar macrophages by cigarette smoking. J. Clin. Invest. 52: 1881-1884.

24. Keimowitz, R. I. 1964. Immunoglobulins in normal human tracheobronchial washings. A qualitative and quantitative study. J. Lab. Clin. Med. 6:3: 54-59.

25. Van Furth, R., and F. Aiuti. 1969. Immunoglobulin synthesis by tissue of the gastro-intestinal and respiratory tracts. Protides Biol. Fluids Proc. Colloq. Bruges. 16: 479-484.

26. Martinez-Tello, F. J., D. G. Braun, and W. A. Blanc. 1968. Immunoglobulin production in bronchial mucosa and bronchial lymph nodes, particularly in cystic fibrosis of the pancreas. J. Immunol. 101: 989-1003.

27. Ishizaka, K., and R. W. Newcomb. 1970. Presence of IgE in nasal washings and sputum from asthmatic patients. J. Allergy. 46: 197-204.

28. Waldman, R. H., C. Virchow, and D. S. Rowe. 1973. IgE levels in external secretions. Int. Arch. Allerg! Appl. Immunol. 44: 242-248.

29. Patterson, R., J. N. Fink, J. J. Pruzansky, C. Reed, M. Roberts, R. Slavin, and C. R. Zeiss. 1973. Serum immunoglobulin levels in pulmonary allergic aspergillosis and certain other lung diseases, with special reference to immunoglobulin E. Am. J. Med. 54: 16-22.

30. Daniele, R. P., M. D. Altose, and D. T. Rowlands, Jr. 1975. Immunocompetent cells from the lower respiratory tract of normal human lungs. J. Clin. Invest. 56: 986-995.

31. Davis, G. S., A. R. Brody, J. N. Landis, W. G. B. Graham, J. E. Craighead, and G. M. Green. 1976. Quantitation of inflammatory activity in interstitial pneumonitis by bronchofiberscopic pulmonary lavage. Chest. 69(Suppl.): 265-266. 